\title{
Review: Current Concepts in Computer-assisted Hip Arthroscopy
}

\begin{tabular}{|c|c|}
\hline Journal: & $\begin{array}{l}\text { The International Journal of Medical Robotics and Computer Assisted } \\
\text { Surgery }\end{array}$ \\
\hline Manuscript ID & RCS-18-0016.R1 \\
\hline Wiley - Manuscript type: & Review Article \\
\hline Date Submitted by the Author: & $\mathrm{n} / \mathrm{a}$ \\
\hline Complete List of Authors: & $\begin{array}{l}\text { Nakano, Naoki; Addenbrooke's Hospital, Department of Trauma \& } \\
\text { Orthopaedic Surgery } \\
\text { Ranawat, Anil; Hospital for Special Surgery } \\
\text { Audenaert, Emmanuel; Ghent University, Orthopaedic Surgery } \\
\text { Khanduja, Vikas; Addenbrooke's - Cambridge University Hospital, } \\
\text { Department of Trauma \& Orthopaedic Surgery }\end{array}$ \\
\hline Anatomy Keywords: & joints \\
\hline \multicolumn{2}{|l|}{ Operation Keywords: } \\
\hline Speciality Keywords: & orthopaedic \\
\hline Technology Keywords: & computer assisted surgery \\
\hline \multicolumn{2}{|l|}{ Additional Keywords: } \\
\hline Abstract: & $\begin{array}{l}\text { In the last } 15 \text { years, hip arthroscopy has become more popular in } \\
\text { addressing femoroacetabular impingement (FAI) because of its minimally } \\
\text { invasive approach. However, assessing the adequacy of bone resection } \\
\text { when correcting FAI can be difficult because the visualisation and spatial } \\
\text { awareness of the joint are poor. The recent development of technology in } \\
\text { the field of computer-assisted/ navigation and robotic surgery in } \\
\text { orthopaedics as a resource for preoperative planning and intraoperative } \\
\text { assistance has been widely reported. As this technology is expected to } \\
\text { upgrade surgical planning and techniques, decrease human error and } \\
\text { improve operative results by precisely defining the divergent anatomy and } \\
\text { kinematics of the hip joint, they could also prove beneficial in the field of } \\
\text { arthroscopic FAI surgery. This review attempts to bring the reader up-to- } \\
\text { date with the current developments in the field, discuss our experience } \\
\text { with navigation and robotics and provide a platform for future research in } \\
\text { this arena. }\end{array}$ \\
\hline
\end{tabular}


1 Review

3 Title: Review: Current Concept in Computer-assisted Hip Arthroscopy

\section{Corresponding Author}

Mr. Vikas Khanduja MA (Cantab), MSc, FRCS (Tr \& Orth)

Consultant Orthopaedic Surgeon \& Associate Lecturer

Department of Trauma and Orthopaedics, Addenbrooke's - Cambridge University Hospitals NHS Foundation Trust Box 37, Hills Road, Cambridge, CB2 OQQ.

Tel: +44 (0) 1223257093

Fax: +44 (0) 1223317207

Email:vk279@cam.ac.uk

Key Words: computer-assisted surgery; navigation; arthroscopy; hip; review

\section{Source of Funding: Nil}

Word counts: 4,015 (From Abstract to Conclusion)

Number of figures: 2

Number of tables: 0 


\begin{abstract}
37 Abstract
38 In the last 15 years, hip arthroscopy has become more popular in addressing

39 femoroacetabular impingement (FAI) because of its minimally invasive approach.

40 However, assessing the adequacy of bone resection when correcting FAI can be

41 difficult because the visualisation and spatial awareness of the joint are poor. The

42 recent development of technology in the field of computer-assisted/ navigation and

43 robotic surgery in orthopaedics as a resource for preoperative planning and

44 intraoperative assistance has been widely reported. As this technology is expected

45 to upgrade surgical planning and techniques, decrease human error and improve

46 operative results by precisely defining the divergent anatomy and kinematics of the

47 hip joint, they could also prove beneficial in the field of arthroscopic FAl surgery.

48 This review attempts to bring the reader up-to-date with the current developments

49 in the field, discuss our experiences with navigation and robotics and provide a

50 platform for future research in this arena.

51
\end{abstract}


Introduction

53 Femoroacetabular impingement (FAl) occurs when the hip joint has an abnormal

54 shape at the femoral head-neck junction (cam-type) or at the acetabular rim of the

55 pelvis (pincer-type). It has been recognised as a major risk factor that may lead to

56 the development of early labral and cartilage damage in the non-dysplastic hip (1-4).

57 Several clinical studies have shown that surgical correction of these osseous

58 abnormalities improves clinical function and relieves hip pain (3,5-7). However, in

59 patients with $\mathrm{FAl}$, due to the complex 3D shape of the offending lesion and the

60 large soft-tissue mantle around the hip joint, the arthroscopic view of the working

61 area can be restricted (8). In addition, evaluation of the sphericity of the femoral

62 head in the treatment of cam-type FAI during hip arthroscopy is difficult $(9,10)$; it is

63 usually done by means of surgical templates (femoral spherometer gauges) during

64 open surgical dislocation.

65

66 Recently, computer-assisted navigation and modelling have emerged as a potential

67 solution to improve the preoperative planning for FAl, including determination of

68 the location and size of pincer/cam lesions, as well as to increase the accuracy of

69 intraoperative correction of the osseous deformity. In this review, we will firstly 
70 outline the recent developments of computer-assisted surgery in orthopaedics, the

71 anatomy of FAI and the current limitations of arthroscopic FAI surgery. We will then

72 describe the evolution of computer-assisted hip arthroscopy to address these

73 limitations, which is divided into two parts; preoperative planning/assessment tools

74 and intraoperative navigation programmes. Lastly, the future of robot-assisted hip

75 arthroscopy is discussed. The aim of this review is to outline the current conditions

76 and challenges in computer-assisted arthroscopic FAI surgery. 


\section{Computer-assisted surgery in orthopaedics}

79

80

81

82

83

84

86

87

The purpose of computer-assisted technology in orthopaedics is to provide patient-specific tools that allow for the reliable implementation of preoperative surgical plans in the operating theatre (11). The ideal goal of this technology would be to integrate high-precision preoperative surgical plans based on prior CT or MRI with actual surgical treatment procedures, by accurate placement of operative tools with quantitative feedback to assess the execution of the surgical plan.

These days, there is little doubt that computer-assisted surgery produces more accurate and precise results, and reduces the learning curve in some types of orthopaedic surgeries, including lower limb joint replacement (total hip replacement and total/unicondylar knee replacement), anterior cruciate ligament reconstruction and trauma and spine surgery (12-16). However, there have not been enough data to support improved outcomes after these navigated operations thus far. For example, although navigated total knee replacement is one of the most popular applications of computer-assisted technology in orthopaedics, no study has been available to validate this technology and prove its long-term benefits (17). Also, while navigation technology has been reported to improve the positioning of 
96 components in unicondylar knee replacement and the acetabular cup positioning in

97 total hip replacement, the assumed benefits of technical precision and

98 reproducibility have not to be correlated with better objective and subjective

99 clinical outcomes yet $(14,18)$. The cost of these systems and the learning curve

100 associated with these new technologies should also be solved before extended

101 application. 
102

103

104

105

106

107

108

109

110

111

112

113

114

115

116

117 It is widely believed that the onset of osteoarthritis (OA) relates to the local

\section{Pathoanatomy of FAl}

The term 'femoroacetabular impingement' was first used in English-language literature in 1999 (19). By definition, FAl is a result of bone abutment of the femoral neck and the acetabulum. Though two distinct types of FAI have been recognised (cam and pincer), most patients present with clinical and radiographic findings which relate to both deformities. Cam impingement refers to a decrease in the femoral head-neck offset, in other words, asphericity of the femoral head-neck junction, which causes a prominent osseous lesion that impinges on the acetabulum. The location of impingement is unique and defined by the proximal-distal, medial-lateral and circumferential margins of the loss of offset; most cam legions impinge with flexion, adduction and internal rotation of the hip. On the other hand, focal pincer impingement lesions cause abnormal edge-loading of the acetabular rim, and it can occur with focal or global acetabular retroversion, coxa profunda or protrusion acetabuli $(20,21)$.

mechanical environment of a joint $(22,23)$. In terms of the hip, cam-type FAl is recognised as an early cause of joint dysfunction, including pain generation, 
120 degeneration and tearing of the labrum which leads to OA $(20,24-27)$. In the patient

121 with FAl, characteristic injury to the labrum and cartilage has been observed, and it

122 is thought to reflect repetitive micro-trauma from the abnormal osseous

123 morphology. The labrum has several functions, such as hip stability, cartilage

124 nutrition, augmentation of femoral head coverage and a so-called joint sealing

125 effect $(28,29)$. The labrum is often the first structure to be affected by pincer

126 impingement due to mechanical impingement between the femoral neck bone and

127 acetabulum with subsequent degeneration or ossification. In contrast, in typical

128 cam impingement, there is early delamination of the cartilage with labral

129 degeneration and detachment over time, as a result of chronic repetitive stress (1).

131 In the surgical management of FAI, both open and arthroscopic approaches can be

132 used. As an open technique, open surgical dislocation of the hip was described to

133 minimise iatrogenic injury to the articular surface and obtain a wide view of the hip

134 joint safely (30). It is, however, not without risks, including non-union after

135 trochanteric osteotomy, avascular necrosis due to disruption of femoral head blood

136 supply and increased morbidity with a large amount of soft tissue dissection (31).

137 Based on this, hip arthroscopy has evolved to correct osseous morphology which 
138 causes impingement, as well as treat both chondral and labral lesions in a minimally

139 invasive manner (32-34). Several authors have reported on arthroscopic treatments

140 for FAl-related pathology with favourable clinical outcomes (32,35-37), but there

141 have been no long-term outcomes. Systematic reviews assessing differences in

142 outcomes between the arthroscopic and open treatment of FAI have also been

143 reported $(34,38)$, and they have concluded that open techniques to address $\mathrm{FAI}$ and

144 labral tears are not superior to arthroscopic methods. 


\section{3. Current limitations of hip arthroscopy for FAI}

147 As our understanding of FAl continues to improve, there is an increased interest in 148 computer-assisted planning and navigation to treat abnormalities associated with

149 FAl. The current limitations of arthroscopic FAl surgery can be divided into two 150 perspectives: preoperative assessment and intraoperative execution. While the 151 long-term clinical outcome may be multifactorial, a reproducible and accurate 152 surgical correction of the deformity may be one of the few variables with FAl which 153 is surgeon-controlled. Therefore, the challenges of preoperative characterisation of 154 the mechanical deformities, as well as the difficulties in intraoperative exposure and 155 correction of impingement regions, make computer-assisted surgical technologies 156 particularly useful.

158 Preoperative planning

159 Preoperative assessment tools, which include imaging modalities such as 160 radiography and $\mathrm{CT}$ and $\mathrm{MRI}$ scanning, are all aimed at providing the surgeon with a 161 patient-specific reconstruction of the osseous anatomy as well as a proper diagnosis.

162 Currently, preoperative planning for arthroscopic FAI is based on these static 163 anatomical models which characterise cam and pincer lesions. It is important to 
164 recognise the osseous anatomical anomalies when planning arthroscopic FAI

165 surgery; in a recent CT-beased study Dolan et al (39) reported that 90\% of patients

166 with symptomatic labral tears had structural abnormalities, such as femoral

167 retroversion or excessive anteversion, coxa valga or acetabular dysplasia which

168 includes lateral and/or anterior under-coverage.

170 Today, the alpha angle is the most used tool for the anatomical surgical planning of

171 FAl. Alpha angle is defined by the axis of the femoral neck and a line connecting the

172 centre of the femoral head to the anterior extent of the concavity of the femoral

173 neck in an MRI slice which is parallel to the axis of the neck and passing through the

174 centre of the femoral head (40). Usually, an alpha angle $<50^{\circ}$, or a reduction of the

175 alpha angle by $20^{\circ}$ (in cases where the alpha angle is very large) is recommended as

176 a target for surgical correction, because this would result in satisfactory restoration

177 of femoral head-neck offset (41). The alpha angle has also been shown to correlate

178 with increased chondral damage, labral injury, decreased range of movement

179 (ROM) and other preoperative symptoms $(42,43)$. It is also useful in assessing

180 surgical correction postoperatively (44). There are, however, some drawbacks to

181 using the alpha angle as a tool. First, as the maximal loss of the head-neck offset is 
182 present at different locations in different patients (45). 2D measurement is not

183 enough to assess the anatomical variances. Secondly, it does not take the length of

184 the cam lesion into account. The resection should be advanced into the trochanteric

185 fossa in the case of a large bump. Thirdly, the alpha angle does not always correlate

186 with the clinical ROM. Brunner et al(46) reported that cam-type FAl patients with

187 insufficient offset correction showed a slightly better internal rotation than patients

188 with satisfactory offset restoration. Lastly, a pathological value of the alpha angle

189 itself has been questioned. Clohisy et al (47) could not define an alpha angle

190 threshold beyond which a pathological diagnosis could be made after evaluating

191 the alpha angle in both FAI patients and normal controls.

\section{Intraoperative execution}

194 The learning curve associated with arthroscopic FAl surgery is often referred to as

195 'steep' $(48,49)$. It is often difficult to undertake a preoperative plan correctly, as it

196 requires not only a high level of arthroscopic skill and good visualisation but also

197 precise identification of the margins of the osseous bump lesion and a proper

198 decision on the amount of bone resection. Even in the hands of experienced hip

199 arthroscopy surgeons, who have achieved adequate exposure, the margins of the 
200 impingement lesion are not always obvious. Patient positioning, cannulation,

201 visualisation and osseous resection are all factors which could lead to potential

202 technical errors.

203

204 Hip arthroscopy surgeons usually combine arthroscopic appearance with

205 fluoroscopy to perform an intraoperative assessment of an adequate resection. The

206 problem with this method is that both of them are a $2 \mathrm{D}$ modality and the $3 \mathrm{D}$

207 morphology is, therefore, constructed only in the surgeon's brain without any

208 objective assessment. Osseous abnormalities are often under-resected, and this is a

209 major cause for revision hip arthroscopy, accounting for up to $78 \%$ to $90 \%$ of all

210 unsuccessful arthroscopic FAl surgery $(50,51)$. It is common for inexperienced

211 surgeons to stop the osseous resection once an adequate image is obtained on

212 fluoroscopy but some cam lesions extend posteriorly or distally and further internal

213 rotation or an accessory portal may show an inadequate resection. Surgeons should

214 bear over-resection of the bone in mind as well. Over-resection of a pincer lesion

215 can result in iatrogenic dysplasia due to acetabular under-coverage, and

216 postoperative instability and dislocation have been reported to be linked to

217 over-resection $(52,53)$. Over-resection beyond the margins of a cam lesion can 
218 damage the cortical bone support of the femoral neck, which may lead to iatrogenic

219 fracture (54). Moreover, in the posterolateral part of the proximal femur, the blood

220 supply to the epiphysis can be damaged by excessive reaming, leading to avascular

221 necrosis (55). These problems reinforce the need for computer-navigated surgical

222 tools which guide surgeons sufficiently during the operation. 


\section{Current navigation technology}

224

Preoperative computer aided assessment

\section{5}

When assessing the deformity and planning for surgical correction preoperatively,

dynamic manipulation of the image using applied algorithms or computer software

as well as virtual 3D reconstruction and visualisation of the hip joint may be

228 beneficial for surgeons.

229

230 Some non-invasive preoperative software programmes which help surgeons localise

231 the zone of impingement, quantify the volume of resection and predict

232 postoperative ROM using both anatomical and kinematic data have been reported 233 on.

234

235

- The first comprehensive preoperative assessment tools ('HipMotion') were

236 developed by Tannast et al (56) in 2007. The system performs a CT-based 3D

237 kinematics analysis of the hip joint to define zones of impingement and then

238 predict improvement in ROM after a virtual resection. It was made to address

239 the need for an accurate kinematic preoperative plan and enhanced visual

240 guidance to the surgeon. The native preoperative ROM is calculated by collision 
241 algorithms which determine ROM based on points at which impingement 242 occurs after defining the hip centre. Then, the system performs a virtual surgical 243 femoral and acetabular resection which prevents an impingement within 244 normal physiological ROM. After that, using the new parameters, virtual 245 postoperative ROM is simulated by reconstructing the hip joint to assess the 246 efficacy of the planned procedure (57). They used concentric range of motion 247 simulation and did not take any hip translations at the end of range of motion 248 into account. The system offers the advantage of calculating the volume of 249 resection based on an impingement-free postoperative ROM, not a desirable 250 postoperative alpha angle. Validation of this software was performed by 251 comparing the virtually predicted ROM with the actual measured ROM of 252 cadaveric hips. Authors also compared the virtual ROM of normal hips with FAI 253 hips and reported that patients with FAI had significantly decreased flexion, $254 \quad$ internal rotation at $90^{\circ}$ of flexion and abduction (56).

256 cam-type impingement, Audenaert et al $(58,59)$ reported that during internal 257 rotation in $90^{\circ}$ of flexion, the central-medial portion of the cam lesion was 258 found to abut against the anterosuperior quadrant of the acetabular cartilage. 
259 Bedi et al (60) measured clinical ROM and calculated virtual ROM using Mimics

260 in FAl patients before and after arthroscopy, and reported excellent correlation

261 in the postoperative improvement between clinical ROM and virtual ROM, with

262 no significant differences by paired Student's t-tests. Mimics is a segmentation

263 software package and does not allow virtual range of motion simulation. Both

264 Audenaert et al and Bedi et al used dedicated software scripts to perform the

265 motion simulation and calculated zones of impingement, and bony shapes were

266 segmented from the CT scan with the Mimics software.

267 'Articulis' (Clinical Graphics, Netherlands) is also a software which automatically

268 performs the 3D segmentation of the CT scans, assesses the deformity, plans

269 for surgical correction and carries out dynamic manipulation of the image. The

270 reliability and accuracy of this system in determining the presence of movement

271 limiting deformities of the femoroacetabulum was validated using a cadaveric

272 model with artificial cam deformities (Figure 1) (61).

273 - The 'Dyonics PLAN Hip Impingement Planning System' (Smith \& Nephew, USA)

274 provides not only a virtual 3D reconstruction and visualisation of the hip joint

275 but also a platform for intraoperative assistance by performing virtual

276 correction and creating a virtual fluoroscopic image that can be compared with 
277 intraoperative fluoroscopic images, thus verifying adequate bony resection.

278 Milone et al (62) demonstrated the effectiveness of this software compared

279 with traditionally reformatted CT scans and plain radiographs.

280 They can also be used postoperatively for the assessment of the amount of osseous

281 shaving in the cam or pincer lesions.

282

283 There are, however, some limitations to the use of these systems. The data are

284 based on a predefined centre of rotation around which the femoral head moves,

285 and they therefore ignore additional translations or detected collisions. Stated

286 another way, the software does not account for the translation which occurs with

287 hip movement, weight-bearing and muscular activation (63). Furthermore, the

288 CT-based model only allows for osseous impingement and its surgical correction

289 with an osteoplasty of the acetabular and femoral bone. It does not account for

290 impingement of periarticular soft tissues such as labrum. Soft-tissue laxity or

291 impingement can affect ROM and clinical outcomes after surgical intervention.

292 Therefore, these systems may overestimate the potential gains in movement that

293 can be achieved after surgery. In addition, there have been no comparative trials to

294 date determining the superiority of using these systems in the clinical setting. 


\section{Intraoperative navigation}

297 Navigation programmes guide the surgeon to precisely reproduce preoperative

298 plans intraoperatively. The components of these types of navigation systems

299 generally consist of these three parts:

300 - Measurement devices to trace the surgical tool;

301 display device to show information about the surgery;

302 marker on the surgical tool.

303

304 Intraoperative navigation requires matching the preoperative 3D-CT scan to the

305 intraoperative situation. This registration process to establish correspondence

306 between both situations can be image-based (using fluoroscopy) or imageless

307 (using a digitised pointer to mark anatomical landmarks on the bone). Both

308 image-based and imageless protocol require an osseous pin with a calibration

309 marker attached to it that can record the motions of the femoral segments and

310 adjust the navigation feedback accordingly, which avoids the necessity to repeat

311 the registration step each time the femoral position is changed. Example of 312 intraoperative navigation is shown in Figure 2. 
314 Developments and outcomes of various intraoperative navigation programmes

315 have been reported recently.

316 - Brunner et al (46) uploaded preoperative CT images of patients into a modified

317 version of BrainLAB Hip-CT (BrainLAB AG, Germany). A C-arm adapter ('Fluoro

318 3D'; Vector Vision, USA) was used to synchronise intraoperative fluoroscopy

319 with the 3D CT dataset. This allowed real-time feedback of surgical instrument

320 placement in relation to the femoral head-neck junction. In 50 cam-type FAI

321 patients who were divided into a navigated arthroscopy group and a without

322 navigation group, the navigation software did not increase the rate of operative

323 success (ROM and non-arthritic hip scores) and surgical time was significantly

324 longer in the navigated group. This might be partially due to the fact that this

325 prototype software did not allow preoperative planning and thus did not

326 highlight the zone of impingement or the amount of resected bone.

327 - Monahan and Shimada (64) were the first to develop an encoder linkage

328 system to track surgical instruments during hip arthroscopy. An encoder is a

329 device which captures tool movement and orientation and it eliminates the

330 problem of occlusion with standard optical tracking systems. The encoder 
331 linkages are calibrated with preoperative, patient-specific 3D imaging data so

332 the position of the surgical tools can be verified with patient anatomy. In other

333 words, the system displays the real-time surgical instrument position relative to

334 patient anatomy on a screen with a preoperatively generated, patient-specific

$3353 \mathrm{D}$ image. The system incorporates soft tissue as well as bone anatomy and

336 therefore. also serves as a useful aid for safe portal placement.

337 Almoussa et al (65) reported that the same shaping accuracy of the femur could

338 be achieved between an experienced surgeon and a novice surgeon when a

339 navigation system was used to treat cam-type FAI. In this study, a preoperative

340 plan was generated from CT scans and the Brain LAB navigation system, and

341 real-time tracking was performed by surgeons using a pointer with marker

342 arrays to ensure resection was performed according to the preoperative plan.

343 The intraoperative images used in this study were dynamic 2D CT scans in

344 sagittal and axial planes of the head-neck junction, rather than a single image of

345 a virtually 3D reconstructed hip. However, the results clearly indicated that

346 navigated arthroscopic surgery based on preoperative imaging and planning

347 may be useful to reduce the steep learning curve of arthroscopic FAl surgery.

348 - Van Houcke et al (66) reported the outcome of randomised controlled trial 
which compared the cam resection accuracy via the conventional hip arthroscopy technique with the navigation technique. Postoperatively, the mean maximal alpha angle improved significantly in the navigated group compared with the conventional group, especially in the 12 o' clock position. However, positioning time and radiation exposure were significantly longer in the navigated group.

study of six hips and found that a combined CT-fluoroscopy matching navigated

359 procedure allowed for a reproducible registration process for navigated FAI surgery

360 at the femoral site, with high precision at the femoral neck and head-neck junction 361 area with mean deviations below $1 \mathrm{~mm}$. Also, using 12 paired cadaver hips with a 362 virtual cam lesion, Audenaert et al (68) reported that the estimated accuracy of 363 image-based registration by means of 3D fluoroscopy had a mean error of $0.8 \mathrm{~mm}$, 364 while the estimated accuracy of imageless registration in the arthroscopic setting 365 was poor, with a mean error of $5.6 \mathrm{~mm}$. Ecker et al (69) developed some 366 computer-assisted planning and navigation software which uses preoperative ROM 
367 analysis on 3D models of patients' pelvic and femoral bone so that a virtual

368 resection can be performed. Intraoperatively, the planned virtual resection area is

369 shown as a highlighted colour-coded distance map, which aids surgeons awareness

370 of the depth of resection. Once the resection is started, the application alters the

371 colour-coded map in real time to prevent excessive or inadequate

372 osteochondroplasty. 


\section{5. Future perspectives: robot-assisted surgery}

374 Robot-assisted surgery is definitely the ultimate surgical technology, defined as a

375 translation from the quantitative assessment produced by navigation to an

376 automated mechanical surgical action by a robot, i.e. a robotic arm mounted with

377 surgical instruments that can automate the entire surgical procedure following a

378 preoperative surgical plan. This provides a greater level of precision, allowing for

379 unmanned or even remote surgery $(9,53,70)$.

380

381 Today, the 'da Vinci' (Intuitive Surgical, USA) telerobotic platform is the most widely

382 used robotic surgical system, and its technical specifications have attracted interest.

383 This system allows the surgeon to sit remotely at a console and control the

384 movements of robotic arms while viewing the operative site in $3 \mathrm{D}$, and it is being

385 used in procedures such as hysterectomies (71), prostatectomies (72) and gastric

386 bypass (73). Currently, robotic hip arthroscopy using this system is feasible only in a

387 cadaveric model (74). However, remote control of articulated instruments with full

388 ROM at the tip might enable parts of the hip joint that are inaccessible with rigid

389 instrumentation to be reached $(75,76)$ and the strong force that the system offers

390 may be sufficient to work effectively with bony structures and to handle the long 
391 distance between skin level and the location of surgery. It is assumed that it would 392 be feasible to use this system to perform basic hip arthroscopy due to the basic 393 similarity of instrument design of laparoscopic and arthroscopic surgery (74). The 394 'Tactile Guidance System' (MAKO Surgical, USA), which is currently used to perform 395 partial knee and total hip replacements, has been applied in a study on 396 robotic-assisted femoral osteochondroplasty for FAI, although it was tested in 397 sawbone models only. Nonetheless, this system appears promising, as its precision 398 and accuracy over freehand surgery have been proven in well-constructed 399 experimental models by Cartiaux et al (77).

401 An overall limitation to robotic arthroscopy is the restricted space inside the hip 402 joint. Therefore, future instruments for robotic hip arthroscopy in patients will have 403 to be both small in diameter and flexible. It is clear that robotic hip arthroscopy is at 404 a very early stage at present. However, robotic technology has the potential to 405 revolutionise hip arthroscopy and extend the number of reachable areas of the joint 406 as well as to enable surgeons to perform more complex and precise tasks in the 407 restricted spaces of the hip. 


\section{Conclusion}

409 The recent advancement of computer-assisted surgery as a resource for

410 preoperative planning and intraoperative assistance in hip arthroscopy has provided

411 more precise surgical planning and the potential for improved operative results.

412 There have been several studies published describing various technologies which

413 have shown potential for increasing surgical precision in treating FAI. However, they

414 are not without limitations, including a steep learning curve, lack of insight into

415 soft-tissue pathology and restriction to only concentric hips. Future comparative

416 trials determining the efficacy of computer-assisted hip arthroscopy surgery are

417 required.

418

419

420 Conflict of Interest

421

422 No benefits in any form have been received or will be received from any commercial

party related directly or indirectly to the subject of this article.

424 
425

426

$427 \quad$ Figure 1

428 Analysis of simulated bony range of motion in Articulis and suggested preoperative

430

431

432

433

434

435

436

437

\section{Legends to figures}

resection plan on the femoral neck in order to normalise the range of motion

defects

\section{Figure 2}

The femoral marker (a) and fluoroscopy (B) are calibrated using the rigid pointer. An intraoperative fluoroscopy scan limited to the proximal femur is performed (C) in order to allow for image based matching of the preoperative plan. Finally, live resection control in relation to the preoperative plan can be performed using the rigid pointer and fluoroscopy is no longer required (D) 


\section{References}

439

440 1. Beck M, Kalhor M, Leunig M, Ganz R. Hip morphology influences the pattern of 441 damage to the acetabular cartilage: femoroacetabular impingement as a cause of 442 early osteoarthritis of the hip. J Bone Joint Surg Br. 2005;87(7):1012-1018.

443 2. Bedi A, Dolan M, Leunig M, Kelly BT. Static and dynamic mechanical causes of hip 444 pain. Arthroscopy. 2011;27(2): 235-251.

445 3. Peters CL, Erickson JA. Treatment of femoro-acetabular impingement with 446 surgical dislocation and debridement in young adults. J Bone Joint Surg Am. 447 2006;88(8): 1735-1741.

448 4. Peters CL, Erickson JA, Anderson L, Anderson AA, Weiss J. Hip-preserving surgery: 449 understanding complex pathomorphology. J Bone Joint Surg Am. 2009;91 Suppl 6: $450 \quad 42-58$.

451 5. Beaule PE, Le Duff MJ, Zaragoza E. Quality of life following femoral head-neck 452 osteochondroplasty for femoroacetabular impingement. J Bone Joint Surg Am. $453 \quad 2007 ; 89(4): 773-779$.

454 6. Byrd JW, Jones KS. Arthroscopic femoroplasty in the management of cam-type 455 femoroacetabular impingement. Clin Orthop Relat Res. 2009;467(3):739-746.

456 7. Laude F, Sariali E, Nogier A. Femoroacetabular impingement treatment using 457 arthroscopy and anterior approach. Clin Orthop Relat Res. 2009;467(3): 747-752.

458 8. Mardones R, Lara J, Donndorff A, Barnes S, Stuart MJ, Glick J, et al. Surgical 459 correction of "cam-type" femoroacetabular impingement: a cadaveric comparison 460 of open versus arthroscopic debridement. Arthroscopy. 2009;25(2):175-182.

461 9. Park CN, Nawabi DH, Christopher J, Conditt MA, Ranawat AS. Robotic-assisted 462 femoral osteochondroplasty is more precise than a freehand technique in a 463 Sawbone model. J Hip Peserv Surg. 2015;2(2):136-144.

464 10. Nawabi DH, Nam D, Park C, Ranawat AS. Hip Arthroscopy: The Use of Computer 465 Assistance. HSS J. 2013;9: 70-78.

466 11. Pearle AD, Kendoff D, Musahl V. Perspectives on computer-assisted orthopaedic 467 surgery: movement toward quantitative orthopaedic surgery. J Bone Joint Surg Am. 468 2009;91 Suppl 1:7-12.

469 12. Haaker RG, Tiedjen K, Ottersbach A, Rubenthaler F, Stockheim M, Stiehl JB. 470 Comparison of conventional versus computer-navigated acetabular component 471 insertion. J Arthroplasty. 2007;22(2):151-159. 
13. Weng YJ, Hsu RW, Hsu WH. Comparison of computer-assisted navigation and conventional instrumentation for bilateral total knee arthroplasty. $J$ Arthroplasty. 2009;24(5):668-673.

475 14. Cobb J, Henckel J, Gomes P, Harris S, Jakopec M, Rodriguez F, et al. Hands-on robotic unicompartmental knee replacement: a prospective, randomised controlled study of the acrobot system. J Bone Joint Surg Br. 2006;88(2):188-197. 15. Seon JK, Song EK. Navigation-assisted less invasive total knee arthroplasty compared with conventional total knee arthroplasty: a randomized prospective trial. J Arthroplasty. 2006;21(6):777-782.

481 16. Voos JE, Musahl V, Maak TG, Wickiewicz TL, Pearle AD. Comparison of tunnel positions in single-bundle anterior cruciate ligament reconstructions using computer navigation. Knee Surg Sports Traumatol Arthrosc. 2010;18(9):1282-1289. 17. Nakano N, Matsumoto T, Ishida K, Tsumura N, Kuroda R, Kurosaka M. Long-term subjective outcomes of computer-assisted total knee arthroplasty. Int Orthop. 2013;37(10):1911-1915.

18. Beckmann J, Stengel D, Tingart M, Götz J, Grifka J, Lüring C. Navigated cup implantation in hip arthroplasty. Acta Orthop. 2009;80(5):538-544.

19. Myers SR, Eijer H, Ganz R. Anterior femoroacetabular impingement after periacetabular osteotomy. Clin Orthop Relat Res. 1999;(363):93-99. 20. Ganz R, Leunig M, Leunig-Ganz K, Harris WH. The etiology of osteoarthritis of 492 the hip: an integrated mechanical concept. Clin Orthop Relat Res. 493 2008;466(2):264-272.

494 21. Laude F, Boyer T, Nogier A. Anterior femoroacetabular impingement. Joint Bone 495 Spine. 2007;74(2):127-132.

496 22. Bijlsma JW, Berenbaum F, Lafeber FP. Osteoarthritis: an update with relevance 497 for clinical practice. Lancet. 2011;377(9783):2115-2126.

498 23. Martel-Pelletier J. Pathophysiology of osteoarthritis. Osteoarthritis Cartilage. 499 2004;12 Suppl A:S31-33.

500 24. Ganz R, Parvizi J, Beck M, Leunig M, Nötzli H, Siebenrock KA. Femoroacetabular 501 impingement: a cause for osteoarthritis of the hip. Clin Orthop Relat Res. 502 2003;(417):112-120.

503 25. Burnett RS, Della Rocca GJ, Prather H, Curry M, Maloney WJ, Clohisy JC. Clinical 504 presentation of patients with tears of the acetabular labrum. J Bone Joint Surg Am. $505 \quad$ 2006;88(7):1448-1457.

506 26. Harris WH. Etiology of osteoarthritis of the hip. Clin Orthop Relat Res. 1986;213: 507 20-33. 
508 27. Philippon MJ, Schenker ML. Arthroscopy for the treatment of femoroacetabular 509 impingement in the athlete. Clin Sports Med. 2006;25(2):299-308, ix.

510 28. Ferguson SJ, Bryant JT, Ganz R, Ito K. The influence of the acetabular labrum on 511 hip joint cartilage consolidation: a poroelastic finite element model. $J$ Biomech. 512 2000;33(8): 953-960.

513 29. Ferguson SJ, Bryant JT, Ganz R, Ito K. An in vitro investigation of the acetabular 514 labral seal in hip joint mechanics. J Biomech. 2003;36(2):171-178.

515 30. Ganz R, Gill TJ, Gautier E, Ganz K, Krügel N, Berlemann U. Surgical dislocation of 516 the adult hip a technique with full access to the femoral head and acetabulum 517 without the risk of avascular necrosis. J Bone Joint Surg Br. 2001;83(8):1119-1124.

518 31. Botser IB, Smith TW Jr, Nasser R, Domb BG. Open surgical dislocation versus 519 arthroscopy for femoroacetabular impingement: a comparison of clinical outcomes. 520 Arthroscopy. 2011;27(2):270-278.

521 32. Byrd JW, Jones KS. Hip arthroscopy in athletes: 10-year follow-up. Am J Sports 522 Med. 2009;37(11):2140-2143.

523 33. Stevens MS, Legay DA, Glazebrook MA, Amirault D. The evidence for hip 524 arthroscopy: grading the current indications. Arthroscopy. 2010;26(10):1370-1383.

525 34. Bedi A, Chen N, Robertson W, Kelly BT. The management of labral tears and 526 femoroacetabular impingement of the hip in the young, active patient. Arthroscopy. 527 2008;24(10):1135-1145.

528 35. Byrd JW, Jones KS. Prospective analysis of hip arthroscopy with 2-year follow-up. 529 Arthroscopy. 2000;16(6):578-587.

530 36. Byrd JW, Jones KS. Prospective analysis of hip arthroscopy with 10-year followup. 531 Clin Orthop Relat Res. 2010;468(3):741-746.

532 37. Larson CM, Ross JR, Stone RM, Samuelson KM, Schelling EF, Giveans MR, et al. 533 Arthroscopic Management of Dysplastic Hip Deformities: Predictors of Success and 534 Failures With Comparison to an Arthroscopic FAl Cohort. Am J Sports Med. 535 2016;44(2):447-453.

536 38. Ng VY, Arora N, Best TM, Pan X, Ellis TJ. Efficacy of surgery for femoroacetabular 537 impingement: a systematic review. Am J Sports Med. 2010;38(11):2337-2345.

538 39. Dolan MM, Heyworth BE, Bedi A, Duke G, Kelly BT. CT reveals a high incidence of 539 osseous abnormalities in hips with labral tears. Clin Orthop Relat Res. $540 \quad$ 2011;469(3):831-838.

541 40. Nötzli HP, Wyss TF, Stoecklin CH, Schmid MR, Treiber K, Hodler J. The contour of 542 the femoral head-neck junction as a predictor for the risk of anterior impingement. $J$ 543 Bone Joint Surg Br. 2002;84(4):556-560. 
41. Stähelin L, Stähelin T, Jolles BM, Herzog RF. Arthroscopic offset restoration in femoroacetabular cam impingement: accuracy and early clinical outcome. Arthroscopy. 2008;24(1):51-57 e1. offset angle alpha and hip chondral injury in femoroacetabular impingement. Arthroscopy. 2008;24(6):669-675.

43. Allen D, Beaulé PE, Ramadan O, Doucette S. Prevalence of associated deformities and hip pain in patients with cam-type femoroacetabular impingement. J Bone Joint Surg Br. 2009;91(5):589-594. 44. de Sa D, Urquhart N, Philippon M, Ye JE, Simunovic N, Ayeni OR. Alpha angle correction in femoroacetabular impingement. Knee Surg Sports Traumatol Arthrosc. 2014;22(4):812-821.

556 45. Pfirrmann CW, Mengiardi B, Dora C, Kalberer F, Zanetti M, Hodler J. Cam and pincer femoroacetabular impingement: characteristic MR arthrographic findings in 50 patients. Radiology. 2006;240(3):778-785.

559 46. Brunner A, Horisberger M, Herzog RF. Evaluation of a computed 560 tomography-based navigation system prototype for hip arthroscopy in the 561 treatment of femoroacetabular cam impingement. Arthroscopy. 2009;25(4):382-391. 562 47. Clohisy JC, Nunley RM, Otto RJ, Schoenecker PL. The frog-leg lateral radiograph 563 accurately visualized hip cam impingement abnormalities. Clin Orthop Relat Res. 2007;462:115-121.

565 48. Konan S, Rhee SJ, Haddad FS. Hip arthroscopy: analysis of a single surgeon's 566 learning experience. J Bone Joint Surg Am. 2011;93 Suppl 2:52-56.

567 49. Souza BG, Dani WS, Honda EK, Ricioli W Jr, Guimarães RP, Ono NK, et al. Do 568 complications in hip arthroscopy change with experience? Arthroscopy. 569 2010;26(8):1053-1057.

570 50. Heyworth BE, Shindle MK, Voos JE, Rudzki JR, Kelly BT. Radiologic and 571 intraoperative findings in revision hip arthroscopy. Arthroscopy. 572 2007;23(12):1295-1302.

573 51. Philippon MJ, Schenker ML, Briggs KK, Kuppersmith DA, Maxwell RB, Stubbs AJ. 574 Revision hip arthroscopy. Am J Sports Med. 2007;35(11):1918-1921.

575 52. Matsuda DK. Acute iatrogenic dislocation following hip impingement 576 arthroscopic surgery. Arthroscopy. 2009;25(4):400-404.

577 53. Ranawat AS, McClincy M, Sekiya JK. Anterior dislocation of the hip after 578 arthroscopy in a patient with capsular laxity of the hip. A case report. J Bone Joint 579 Surg Am. 2009;91(1):192-197. 
54. Mardones RM, Gonzalez C, Chen Q, Zobitz M, Kaufman KR, Trousdale RT.

581 Surgical treatment of femoroacetabular impingement: evaluation of the effect of

582 the size of the resection. Surgical technique. J Bone Joint Surg Am. 2006;88 Suppl 1 583 Pt 1:84-91.

584 55. Sussmann PS, Zumstein M, Hahn F, Dora C. The risk of vascular injury to the 585 femoral head when using the posterolateral arthroscopy portal: cadaveric 586 investigation. Arthroscopy. 2007; 23(10):1112-1115.

587 56. Tannast M, Kubiak-Langer M, Langlotz F, Puls M, Murphy SB, Siebenrock KA. 588 Noninvasive three-dimensional assessment of femoroacetabular impingement. J 589 Orthop Res. 2007;25(1):122-131.

590 57. Kubiak-Langer M, Tannast M, Murphy SB, Siebenrock KA, Langlotz F. Range of 591 motion in anterior femoroacetabular impingement. Clin Orthop Relat Res. 592 2007;458:117-124.

593 58. Audenaert EA, Mahieu P, Pattyn C. Three-dimensional assessment of cam 594 engagement in femoroacetabular impingement. Arthroscopy. 2011;27(2):167-171.

595 59. Audenaert EA, Vigneron L, Pattyn C. A method for three-dimensional evaluation 596 and computer aided treatment of femoroacetabular impingement. Comput Aided 597 Surg. 2011;16(3):143-148.

598 60. Bedi A, Dolan M, Hetsroni I, Magennis E, Lipman J, Buly R, et al. Surgical 599 treatment of femoroacetabular impingement improves hip kinematics: a 600 computer-assisted model. Am J Sports Med. 2011;39 Suppl:43S-49S.

601 61. Röling MA, Visser MI, Oei EH, Pilot P, Kleinrensink GJ, Bloem RM. A quantitative 602 non-invasive assessment of femoroacetabular impingement with CT-based dynamic 603 simulation--cadaveric validation study. BMC Musculoskelet Disord. 2015;16:50.

604 62. Milone MT, Bedi A, Poultsides L, Magennis E, Byrd JW, Larson CM, et al. Novel 605 CT-based three-dimensional software improves the characterization of cam 606 morphology. Clin Orthop Relat Res. 2013;471(8):2484-2491.

607 63. Puls M, Ecker TM, Tannast M, Steppacher SD, Siebenrock KA, Kowal JH. The 608 Equidistant Method - a novel hip joint simulation algorithm for detection of 609 femoroacetabular impingement. Comput Aided Surg. 2010;15(4-6):75-82.

610 64. Monahan E, Shimada K. Computer-aided navigation for arthroscopic hip surgery 611 using encoder linkages for position tracking. Int J Med Robot. 2006;2(3):271-278.

612 65. Almoussa S, Barton C, Speirs AD, Gofton W, Beaulé PE. Computer-assisted 613 correction of cam-type femoroacetabular impingement: a Sawbones study. $J$ Bone 614 Joint Surg Am. 2011;93 Suppl 2:70-75.

615 66. Van Houcke J, Khanduja V, Nakano N, Krekel P, Pattyn C, Audenaert E. Accuracy 
616 of navigated cam resection in femoroacetabular impingement: A randomised 617 controlled trial. Int J Med Robot. 2017;13(4).

618 67. Kendoff D, Citak M, Stueber V, Nelson L, Pearle AD, Boettner F. Feasibility of a 619 navigated registration technique in FAl surgery. Arch Orthop Trauma Surg. 620 2011;131(2):167-172.

621 68. Audenaert E, Smet B, Pattyn C, Khanduja V. Imageless versus image-based 622 registration in navigated arthroscopy of the hip: a cadaver-based assessment. J 623 Bone Joint Surg Br. 2012;94(5):624-629.

624 69. Ecker TM, Puls M, Steppacher SD, Bastian JD, Keel MJ, Siebenrock KA, et al. 625 Computer-assisted femoral head-neck osteochondroplasty using a surgical milling 626 device an in vitro accuracy study. J Arthroplasty. 2012;27(2):310-306.

627 70. Advincula AP. Surgical techniques: robot-assisted laparoscopic hysterectomy 628 with the da Vinci surgical system. Int J Med Robot. 2006;2(4):305-311.

629 71. Soto E, Lo Y, Friedman K, Soto C, Nezhat F, Chuang L, et al. Total laparoscopic 630 hysterectomy versus da Vinci robotic hysterectomy: is using the robot beneficial? $J$ 631 Gynecol Oncol. 2011;22(4):253-259.

632 72. Parsons JK, Messer K, Palazzi K, Stroup SP, Chang D. Diffusion of surgical 633 innovations, patient safety, and minimally invasive radical prostatectomy. JAMA 634 Surg. 2014;149(8):845-851.

635 73. Myers SR, McGuirl J, Wang J. Robot-assisted versus laparoscopic gastric bypass: 636 comparison of short-term outcomes. Obes Surg. 2013;23(4):467-473.

637 74. Kather J, Hagen ME, Morel P, Fasel J, Markar S, Schueler M. Robotic hip 638 arthroscopy in human anatomy. Int J Med Robot. 2010;6(3):301-305.

639 75. Hagen ME, Inan I, Pugin F, Morel P. (The da Vinci surgical system in digestive 640 surgery). Rev Med Suisse. 2007;3(117):1622-1626.

641 76. Jacobs S, Falk V. Pearls and pitfalls: lessons learned in endoscopic robotic 642 surgery- the da Vinci experience. Heart Surg Forum. 2001;4(4):307-310.

643 77. Cartiaux O, Paul L, Docquier PL, Raucent B, Dombre E, Banse X. 644 Computer-assisted and robot-assisted technologies to improve bone-cutting 645 accuracy when integrated with a freehand process using an oscillating saw. $J$ Bone 646 Joint Surg Am. 2010;92(11):2076-2082. 
1 Figure 1

2

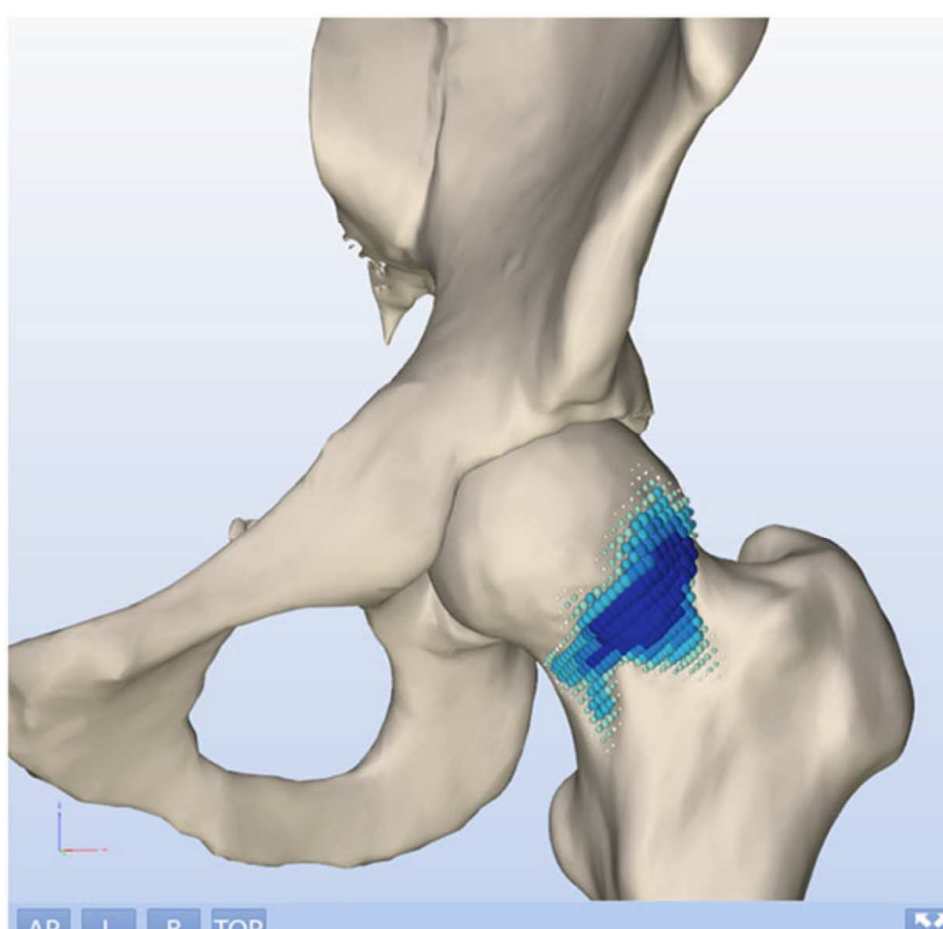

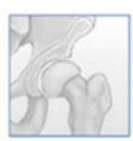

CT

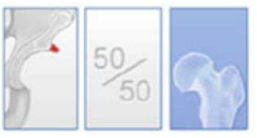

RESECTION

\begin{tabular}{|c|c|}
\hline FLEXION & $109^{\circ}$ of 120 \\
\hline ABDUCTION & $50^{\circ}$ of $50^{\circ}$ \\
\hline INTERNAL & $50^{\circ}$ of $50^{\circ}$ \\
\hline IN with $50 \mathrm{ABD}$ & $40^{\circ}$ of $40^{\circ}$ \\
\hline EXT with $50 \mathrm{ABD}$ & $10^{\circ}$ of $40^{\circ}$ \\
\hline IN with $90 \mathrm{FL}$ & $8^{\circ}$ of $30^{\circ}$ \\
\hline IN with $30 \mathrm{FL}, 20 \mathrm{AD}$ & $50^{\circ}$ of $50^{\circ}$ \\
\hline IN with $60 \mathrm{FL}, 20 \mathrm{AD}$ & $40^{\circ}$ of $40^{\circ}$ \\
\hline IN with $90 \mathrm{FL}, 20 \mathrm{AD}$ & $13^{\circ}$ of $30^{\circ}$ \\
\hline EXT with 15 EXL & $15^{\circ}$ of $15^{\circ}$ \\
\hline
\end{tabular}


Figure 2

2
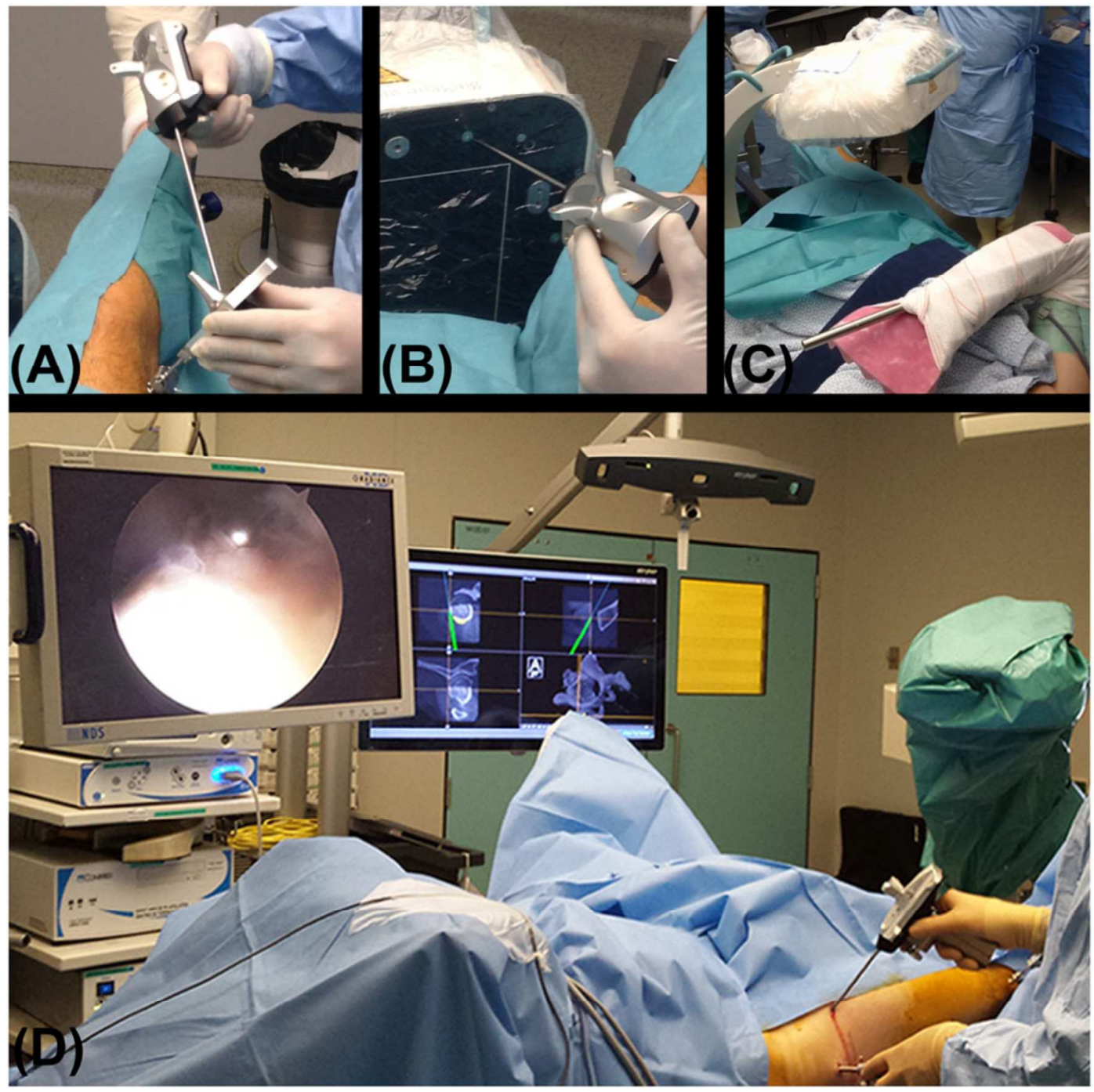